\title{
Brugada Pattern in Diabetic Ketoacidosis: A Case Report and Scoping Study
}

\author{
Syed Haseeb ${ }^{1, \#}$, Pramod Theetha Kariyanna ${ }^{1, \#}$, Apoorva Jayarangaiah ${ }^{2}$, Ganesh Thirunavukkarasu ${ }^{1}$, \\ Sudhanva Hegde ${ }^{1}$, Jonathan D. Marmur ${ }^{1}$, Sneha Neurgaonkar', Samy I. McFarlane ${ }^{1, "}$ \\ ${ }^{1}$ Division of Cardiovascular Disease and Department of Internal Medicine, State University of New York, Downstate Medical Center, \\ Brooklyn, New York, U.S.A- 11203 \\ ${ }^{2}$ Department of Internal Medicine, Wake Forest University, Baptist Health System, Winston-Salem, North Carolina, U.S.A-27157 \\ ${ }^{\#}$ These authors contributed equally to this work. \\ *Corresponding author: Samy.mcfarlane@downstate.edu
}

Received August 05, 2018; Revised September 10, 2018; Accepted October 07, 2018

\begin{abstract}
Brugada syndrome is a rare cardiac arrhythmia which is associated with right bundle branch block pattern (RBBB) and ST-segment elevation in right precordial leads. SCNA5 mutation is the most common genetic abnormality associated with Brugada syndrome. Brugada pattern not related to genetic mutations has been previously reported in the setting of fever, metabolic conditions, lithium use, marijuana and cocaine abuse, ischemia and pulmonary embolism, myocardial and pericardial diseases. Multiple isolated cases of Brugada pattern associated with diabetic ketoacidosis (DKA) have been previously reported. We here present a case of type 1 Brugada pattern in a 23 year-old-male who presented with DKA. Brugada pattern in DKA is attributed to acidosis and multiple electrolyte abnormalities including hyperkalemia which alter ion channel expression in the heart thus leading to Brugada pattern which subsequently resolved with treatment of DKA. In such patients, Brugada pattern is not reproducible on procainamide induction cardiac electrophysiology study (EPS). Our scoping study demonstrates male predominance 20/22 cases of (DELETE this highlighted area) Brugada pattern in DKA, a finding that is consistent with prevalence of this disease among males.
\end{abstract}

Keywords: Brugada pattern, diabetic ketoacidosis

Cite This Article: Syed Haseeb, Pramod Theetha Kariyanna, Apoorva Jayarangaiah, Ganesh Thirunavukkarasu, Sudhanva Hegde, Jonathan D. Marmur, Sneha Neurgaonkar, and Samy I. McFarlane, "Brugada Pattern in Diabetic Ketoacidosis: A Case Report and Scoping Study." American Journal of Medical Case Reports, vol. 6, no. 9 (2018): 173-179. doi: 10.12691/ajmcr-6-9-2.

\section{Introduction}

Brugada syndrome is a rare cardiac arrhythmia which is associated with right bundle branch block pattern (RBBB) and ST-segment elevation in right precordial leads [1]. Brugada Syndrome is associated with life-threatening arrhythmias and/or sudden cardiac death in the absence of underlying structural heart disease [1]. The overall prevalence of a Brugada type electrocardiogram in the United States is approximately $0.43 \%$. It is a familial syndrome that is more likely to present in males. Interestingly male to female disease presentation was noted to be higher in Japan compared to the United States at 9: 1 and 2: 1 ratios respectively [2,3,6]. Multiple genetic mutations have been isolated in cardiac sodium, potassium, calcium, and protein regulatory channels; it is most commonly attributed to one gene: SCN5A, which encodes an $\alpha$-subunit of a sodium channel, in an autosomal dominant pattern of inheritance $[4,5]$.

Brugada pattern can be "induced" by administration of sodium channel blockers such as flecainide, procainamide, and ajmaline [6]. One international registry lists Brugada pattern in patients with metabolic conditions, mechanical compression, ischemia and pulmonary embolism, myocardial and pericardial disease, and ECG modulation [7]. Furthermore, Brugada pattern has been noted in patients in Diabetes Ketoacidosis (DKA) in the setting of extreme electrolyte disturbances including hyperkalemia, hyponatremia, hyperglycemia, and acidosis; it resolves with the appropriate and timely management of the DKA [8]. Flecainide, a potent class IC antiarrhythmic, failed to successfully "induce" Brugada in a case which initially presented with this pattern in the setting of DKA [8]. We here present a case of DKA with a Brugada pattern on initial ECG which resolved with treatment of DKA and underlying electrolyte disturbances, serial ECGs performed showed a rapid resolution of this pattern.

\section{Case Report}

A 23-year-old Afro-Caribbean male with a past medical history of tobacco use and type 1 Diabetes Mellitus since nine years of age presented with DKA. Patient's diabetes 
was managed by continuous insulin infusion for nine years however he reported non-adherence due to insulin pump malfunction over the past week. He reported nausea, several episodes of vomiting, fatigue, polydipsia, and a non-productive cough at home without any polyuria or dysuria at the time of presentation.

On arrival patient's vitals presented as blood pressure of $103 / 52 \mathrm{~mm} \mathrm{Hg}$, heart rate of 110 beats per min, afebrile, respiring at 30 breaths per minute saturating $92 \%$. On physical exam, the patient appeared lethargic with labored breathing. The laboratory findings on the day of admission are summarized in Table 1.

Admission electrocardiogram revealed atrial fibrillation, right bundle branch block (RBBB), and coved ST-segment elevations in leads V1-V3 consistent with a Brugada pattern (image 1). A bedside echocardiogram showed no wall motion or valvular abnormalities, no pericardial effusion, and the ejection fraction was estimated to be $60 \%$.

The patient was treated for DKA with subsequent resolution of hyperkalemia, hyponatremia, hyperglycemia, and metabolic acidosis. Initial labs revealed sodium $103 \mathrm{mmol} / \mathrm{L}$, potassium $8.6 \mathrm{mmol} / \mathrm{L}$, random blood sugar $1313 \mathrm{mg} / \mathrm{dl}$, bicarbonate $5.5 \mathrm{mmol} / \mathrm{L}$, blood urea nitrogen $62 \mathrm{mg} / \mathrm{dl}$, and serum creatinine as $2.69 \mathrm{mg} / \mathrm{dl}$. Repeat labs within 6-9 hours of admission showed significant improvement as shown in Table 1. ECG performed within two hours demonstrated complete resolution of atrial fibrillation and the Brugada pattern. The day after presentation the patient's ECG has returned completely to baseline with complete resolution of all changes and his labs improved further to $\mathrm{Na} 134 \mathrm{mmol} / \mathrm{l}, \mathrm{K} 4.1 \mathrm{mmol} / \mathrm{l}$, random blood sugar $259 \mathrm{mg} / \mathrm{dl}$, bicarbonate $11 \mathrm{mmol} / \mathrm{l}$, blood urea nitrogen $48 \mathrm{mg} / \mathrm{dl}$, creatinine $1.78 \mathrm{mg} / \mathrm{dl}$. He did not have any life-threatening arrhythmias on telemetry monitoring and subsequent imaging with a transthoracic echocardiogram showed no structural changes. $\mathrm{CHA}_{2} \mathrm{DS}_{2}$-VASc Score for atrial fibrillation stroke risk was calculated as one and therefore anticoagulation was not initiated after discussing risks and benefits with the patient.

\section{Discussion}

Brugada pattern is a unique entity, unlike Brugada syndrome, where certain physiologic changes can predispose to life-threatening arrhythmias and sudden cardiac death in the absence of known underlying genetic mutations and/or structural heart disease. Though it is not clear why patients in DKA develop a Brugada pattern, the proposed mechanism revolves around inactivation of the cardiac sodium channels secondary to hyperkalemia and acidosis [9]. Male predominance can be attributed to a more prominent outward current-mediated action potential found in the right ventricular epicardium of males [9]. The pattern resolves immediately with the treatment of the underlying disturbance associated with DKA and was seen within two hours of treatment in our case. Table 3 lists a number of similar cases where Brugada pattern presented after an initial presentation of DKA.

Table 1. Laboratory trends from admission to 24 hours post treatment

\begin{tabular}{|l|c|c|c|}
\hline & $0(\mathrm{hrs})$ & $6-9(\mathrm{hrs})$ & $24(\mathrm{hrs})$ \\
\hline Venous blood $\mathrm{pH}$ & 6.95 & 7.36 & 7.44 \\
\hline Bicarbonate (mmol/L) & 5.5 & 6.0 & 11.0 \\
\hline Sodium (mmol/L) & 103 & 124 & 134 \\
\hline Potassium (mmol/L) & 8.6 & 4.7 & 4.1 \\
\hline Random Blood Glucose (mg/dl) & 1313 & 612 & 259 \\
\hline Blood Urea Nitrogen (mg/dl) & 62 & 58 & 48 \\
\hline Creatinine (mg/dl) & 2.69 & 2.04 & 1.78 \\
\hline B-hydroxybutyrate (mmol/L) & $>8.00$ & - & - \\
\hline Troponins (mmol/L) & 0.02 & - & 0.02 \\
\hline
\end{tabular}

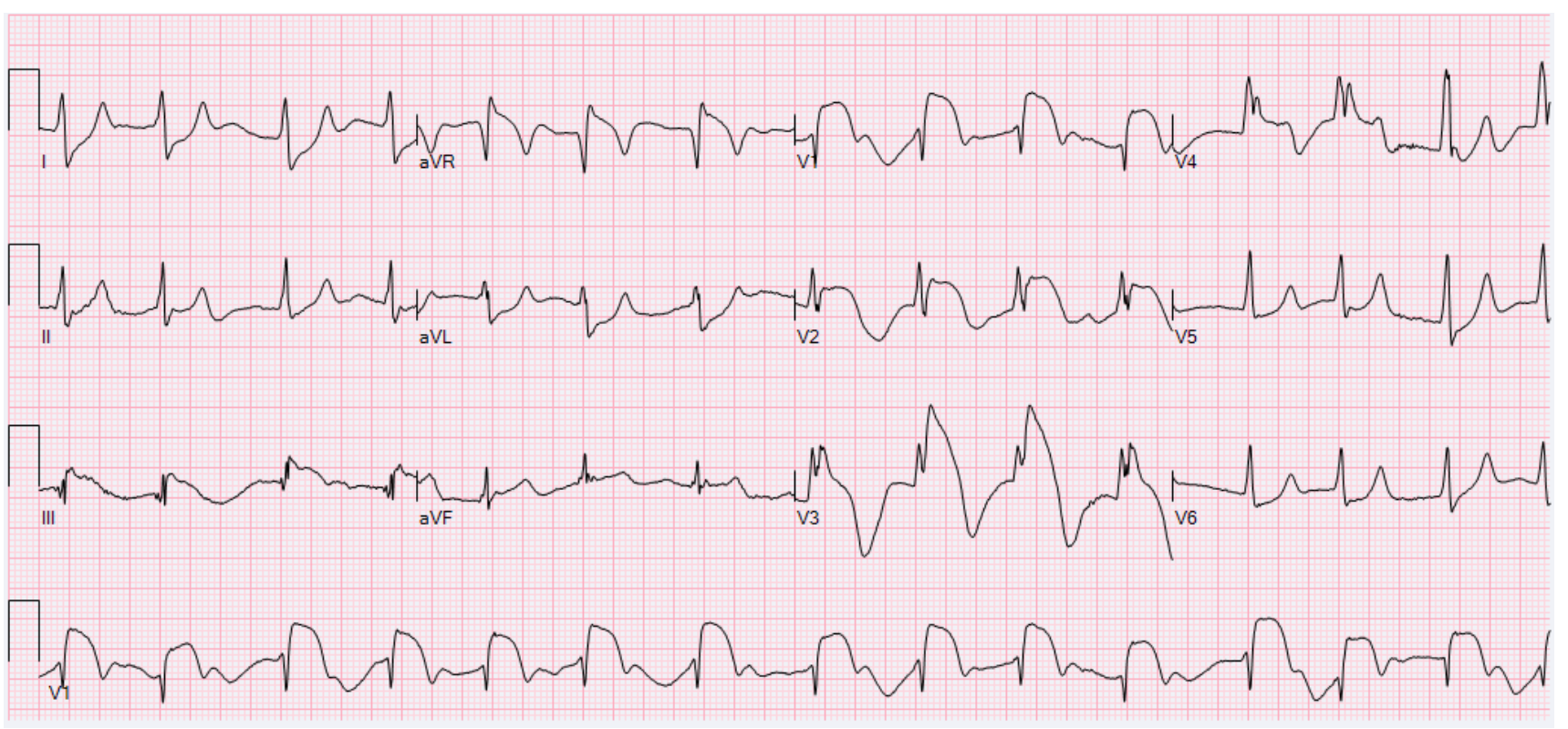

Image 1. Patient's initial ECG: Atrial fibrillation and coved ST-segment elevations with RBBB consistent with a Type 1 Brugada pattern 


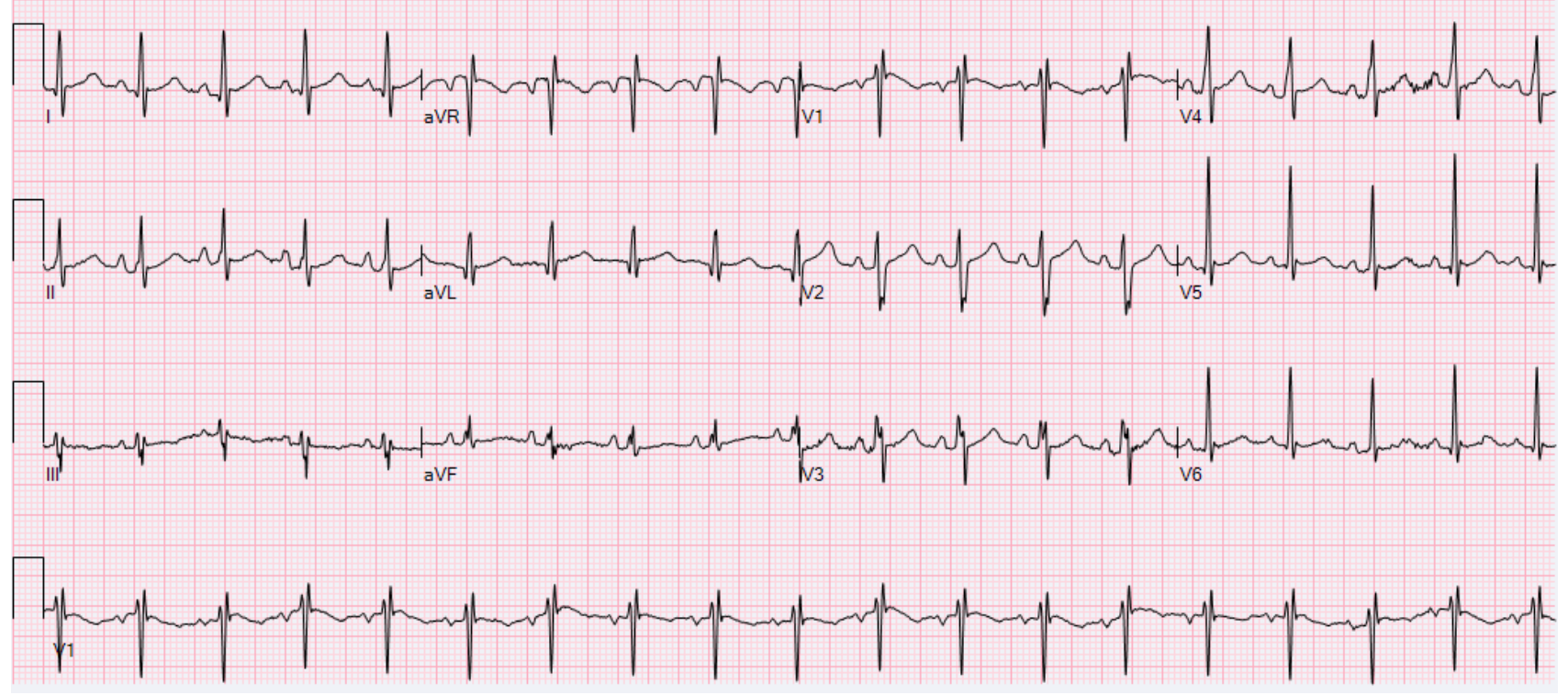

Image 2. ECG obtained two hours after initiation of DKA management showing conversion into normal sinus rhythm and resolution of Brugada pattern

Table 2. Other Precipitating Factors in Literature

\begin{tabular}{|c|}
\hline Schizophrenia [10] \\
\hline Fever [11-16] \\
\hline Illicit Drugs: Cocaine Abuse [17,18] Marijuana [19,20,21,22] \\
\hline Medications: Lithium [23,24,25], SSRI [26,27], Diphenhydramine [28[, TCA [29] \\
\hline Anatomic Compression - Rheumatoid Arthritis [30] \\
\hline Adrenocortical insufficiency [31] \\
\hline
\end{tabular}

Table 3. Literature review of 22 cases of Brugada-type Pattern in DKA

\begin{tabular}{|c|c|c|c|c|c|c|c|c|}
\hline Author & Age & Sex & $\mathrm{pH}$ & $\begin{array}{l}\text { Glucose } \\
(\mathrm{mg} / \mathrm{dl})\end{array}$ & $\begin{array}{c}\text { Sodium } \\
(\mathrm{mmol} / \mathrm{L})\end{array}$ & $\begin{array}{c}\text { Potassium } \\
(\mathrm{mmol} / \mathrm{L})\end{array}$ & $\begin{array}{c}\text { Bicarbonate } \\
(\mathrm{mmol} / \mathrm{L})\end{array}$ & Echo \\
\hline 1978, Chawla et al. [32] & 48 & Male & 7.09 & 840 & - & 8.3 & 6.8 & - \\
\hline 1981, Cohen et al. [33] & 38 & Male & 6.94 & 1206 & 123 & 7.5 & 4 & - \\
\hline 1983, Johnson et al. [34] & 48 & Male & 7.17 & 900 & 130 & 5.8 & 5 & - \\
\hline 1988, Simon et al. [35] & 59 & Male & 7.06 & 1664 & 127 & 8.1 & 5 & - \\
\hline 1992, Kamimura et al. [36] & 45 & Male & 7.01 & 1827 & 127 & 7.2 & 5 & - \\
\hline 1996, Sweterlitsch et al. [37] & 46 & Male & 6.97 & 1586 & 132 & 7.9 & $<5$ & - \\
\hline 1998, YH Lim et al. [38] & 59 & Female & 6.74 & 1021 & 133 & 7.2 & $<5$ & - \\
\hline 2003, Milionis et al. [39] & 65 & Male & 7.07 & 485 & 102 & 8.3 & 13.7 & - \\
\hline 2004, Kovacic et al. [8] & 38 & Male & 6.96 & 1232 & 105 & 7 & $<5$ & normal \\
\hline 2004, Wang et al. [40] & 38 & Male & 7.21 & 839 & - & 7.9 & - & - \\
\hline 2005, Cook et al. [41] & 60 & Male & - & 543 & 128 & 8.4 & 19 & - \\
\hline 2011, Postema et al. [42] & 59 & Male & 7.21 & 828 & - & 6.9 & 7.3 & normal \\
\hline 2012, Ersan et al. [43] & 26 & Male & 7.2 & 620 & - & 7.7 & - & normal \\
\hline 2013, Franco et al. [44] & 44 & Male & - & 501 & - & 7.4 & 6 & $\begin{array}{l}\text { Normal LV systolic } \\
\text { function and wall motion }\end{array}$ \\
\hline 2015, Arunothayaraj et al. [45] & 35 & Male & 6.97 & - & - & 7.6 & - & - \\
\hline 2016, Maheshwari et al. [46] & 65 & Male & - & - & - & 6.8 & - & - \\
\hline 2017, Omar et al. [47] & 31 & Male & 7.05 & 1090 & 126 & 8.4 & 2.8 & - \\
\hline 2017, Dendramis et al. [48] & 72 & Male & 7.35 & - & 130 & 8.7 & 22.6 & $\begin{array}{c}\text { Normal wall motion, EF: } \\
60 \%\end{array}$ \\
\hline 2017, Mehta et al. [49] & 62 & Female & 6.87 & 634 & - & - & 2 & - \\
\hline 2018, Alanzalon et al. [50] & 18 & Male & 6.97 & 1128 & 120 & 7.7 & $<7$ & - \\
\hline 2018, Alanzalon et al. [50] & 7 & Male & 7.14 & 313 & 124 & 4.4 & $<7$ & - \\
\hline 2018, Abrahim et al. [51] & 47 & Female & - & - & - & 6.7 & - & - \\
\hline
\end{tabular}


Table 4. ECG findings from the 22 reported cases

\begin{tabular}{|c|c|}
\hline Author & ECG \\
\hline 1978, Chawla et al. [32] & ST-segment elevation in V1-V2 and AVL, tall peaked T waves in V3 -V6 \\
\hline 1981, Cohen et al. [33] & $\begin{array}{l}\text { irregular rhythm, no P waves, peaked T waves I, II, AVL, V4-V6, Q waves in V3R to V2, broad R wave V3R to V2 } \\
\text { w/ wide S waves in left precordial, and ST elevation V3R to V3 }\end{array}$ \\
\hline 1983, Johnson et al. [34] & $\begin{array}{l}\text { sinus tachycardia, right axis deviation, broadened QRS, right bundle branch block pattern, peaked } \mathrm{T} \text { waves and } \mathrm{ST} \\
\text { elevation in AVL, V1-V3 }\end{array}$ \\
\hline 1988, Simon et al. [35] & $\begin{array}{l}\text { Normal sinus rhythm, ST elevation in V1-V3, peaked T waves, broad flat P waves, right bundle branch block, and } \\
\text { LAFH }\end{array}$ \\
\hline 1992, Kamimura et al. [36] & $\begin{array}{l}\text { sinus tachycardia, QRS widening, right bundle branch block, Q waves V1-V2, ST elevation in V1-V3, peaked T- } \\
\text { waves in V4-V6 }\end{array}$ \\
\hline 1996, Sweterlitsch et al. [37] & $\begin{array}{l}\text { ST elevation anteroseptal leads. No Q waves. An intraventricular conduction similar to a right bundle-branch block } \\
\text { with a delayed rightward voltage }\end{array}$ \\
\hline 1998, YH Lim et al. [38] & Sinus tachycardia. pathologic Q-waves with ST elevation in V1-V3 \\
\hline 2003, Milionis et al. [39] & $\begin{array}{l}\text { Absent P waves widened QRS "sine wave" in leads: I, II, V5-V6, ST depression segments, and tall peaked T waves } \\
\text { V3-V6 }\end{array}$ \\
\hline 2004, Kovacic et al. [8] & Irregular supraventricular rhythm, right axis deviation, right bundle branch block, ST elevation precordial leads \\
\hline 2004, Wang et al. [40] & Sinus tachycardia and ST elevation in leads V1-V3. Peaked T waves in II, III, aVF, and V3-V6 \\
\hline 2005, Cook et al. [41] & $\begin{array}{l}\text { No p-waves accelerated junctional rhythm. ST elevation in V1-V2 and ST depression in I, aVL, and V4-V6. ST- } \\
\text { depression and T-wave inversion in the inferior wall leads. }\end{array}$ \\
\hline 2011, Postema et al. [42] & Convex ST elevation in right precordial leads \\
\hline 2012, Ersan et al. [43] & Right bundle branch block, peaked T waves, ST elevation in V1-V3 \\
\hline 2013, Franco et al. [44] & "coved" ST elevation in V1 and V3 and "saddleback" ST elevation in lead V2 \\
\hline 2015, Arunothayaraj et al. [45] & Brugada pattern, ST elevation in V1-V2, peaked $\mathrm{T}$ and flat $\mathrm{P}$ waves \\
\hline 2016, Maheshwari et al. [46] & $>2 \mathrm{~mm}$ coved ST elevation with T-wave inversion in leads V1 and V2 \\
\hline 2017, Omar et al. [47] & $\begin{array}{l}\text { Hyperacute } \mathrm{T} \text { waves, Brugada type } 1 \text {, prolonged QRS, ST elevation inV1-V2, downsloping ST, and symmetric } \mathrm{T} \\
\text { wave inversions. }\end{array}$ \\
\hline 2017, Dendramis et al. [48] & Sinus bradycardia and a "coved" type-1 Brugada pattern in V1- V2 and a "saddleback" type-2 in V3-V4 \\
\hline 2017, Mehta et. al. [49] & Type 1 Brugada pattern in V1-V2, with ST depressions in the anterolateral leads \\
\hline 2018, Alanzalon et al. [50] & Type 1 brugada pattern \\
\hline 2018, Alanzalon et al.[50] & Type 1 brugada pattern \\
\hline 2018, Abrahim et al. [51] & ST elevation V1-V3 and associated T wave inversions \\
\hline
\end{tabular}

Table 5. Mean and median values of the collected data from table 3a

\begin{tabular}{|l|c|c|}
\hline & Mean & Median \\
\hline Age (years) & 45.90 & 46.5 \\
\hline $\mathrm{pH}$ & 7.054 & 7.055 \\
\hline Glucose $(\mathrm{mg} / \mathrm{dl})$ & 958.7 & 870 \\
\hline Sodium $(\mathrm{mmol} / \mathrm{L})$ & 123.6 & 127 \\
\hline Potassium $(\mathrm{mmol} / \mathrm{L})$ & 7.424 & 7.60 \\
\hline Bicarbonate $(\mathrm{mmol} / \mathrm{L})$ & 7.7 & 5.5 \\
\hline
\end{tabular}

Other potential triggers of Brugada pattern are summarized by cases in Table 2 . There has been a high prevalence in a patient diagnosed with schizophrenia, however, the association was not found to have a correlation with sodium channel blocking medications often prescribed in schizophrenia [10]. Febrile states have been theorized to modulate sodium channels and provoke Brugada syndrome perhaps through missense mutations of T1620M [11] and several cases have been reported to date $[12,13,14,15,16]$. Illicit drugs such as cocaine and marijuana have been listed as triggers. Cocaine a potent sympathomimetic was isolated as a trigger in two case reports with one case repeatedly presenting with Brugada pattern within 2-5 days of cocaine use. Mechanisms have been proposed to involve both increases in overall norepinephrine and sodium blocking properties predisposing to arrhythmias $[17,18]$. Marijuana's proposed mechanism is due to vagal stimulation by cannabis which has previously seen to trigger Brugada Syndrome [19,20,21,22]. Medication use with SSRI and Lithium as triggers have been reported as well. Both medications are potent blockers of cardiac sodium channels and can provoke Brugada syndrome in patients [23,24,25,26,27]. Medication overdose including diphenhydramine and tricyclic antidepressant has been isolated as triggers of arrhythmias and proposed mechanism is attributed anticholinergic overactivity $[28,29]$. One reported case has found a rare complication of hemopericardium and tumor formation from underlying rheumatoid arthritis which compressed the ventricle and unmasked a Brugada pattern [30]. Adrenocortical insufficiency which is commonly associated with hyperkalemia can decrease resting membrane potential inactivating cardiac sodium channels and produce similar findings [31]. 

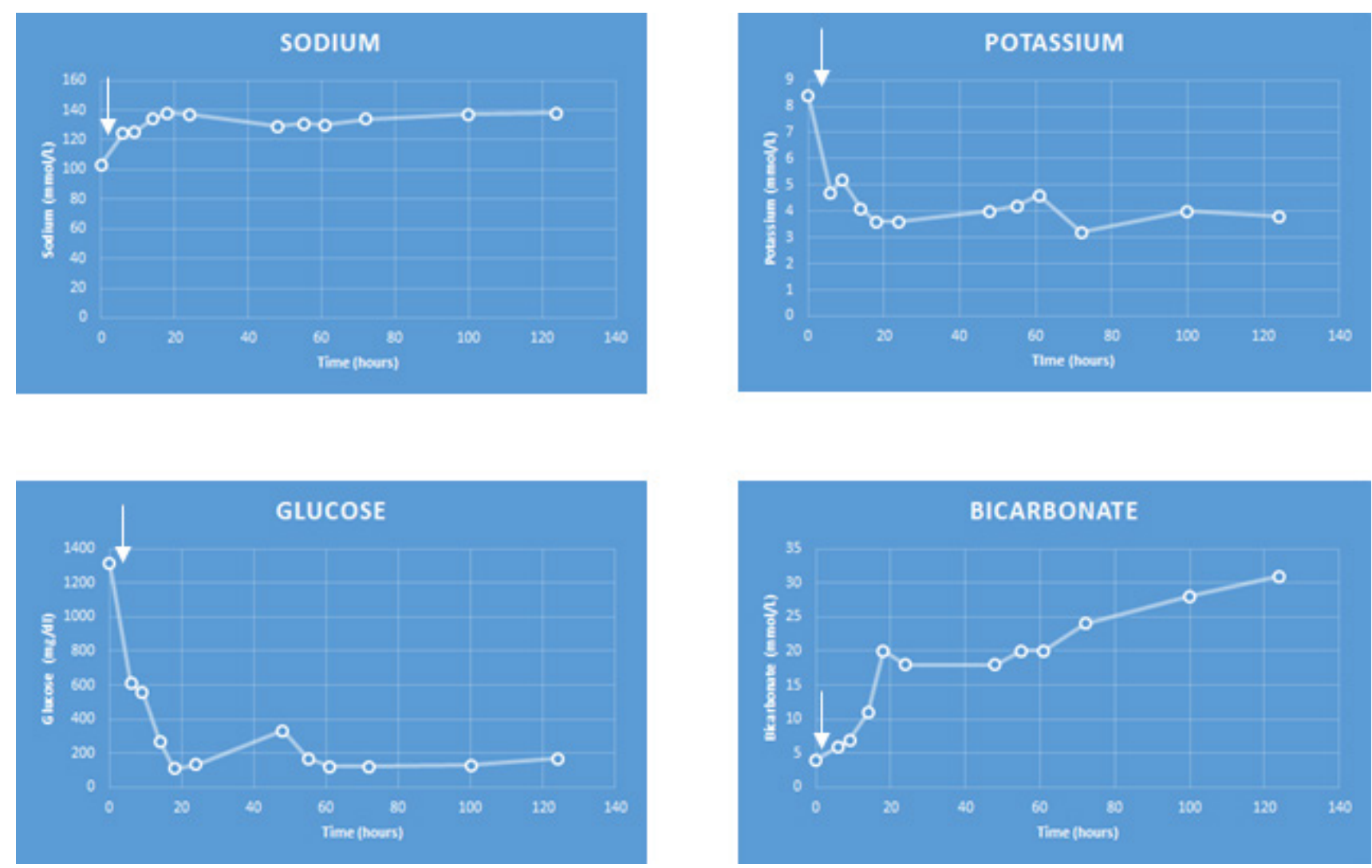

Figure 1. Trends of sodium, potassium, glucose, and bicarbonate levels (white arrow indicating time line at which Brugada pattern resolved)

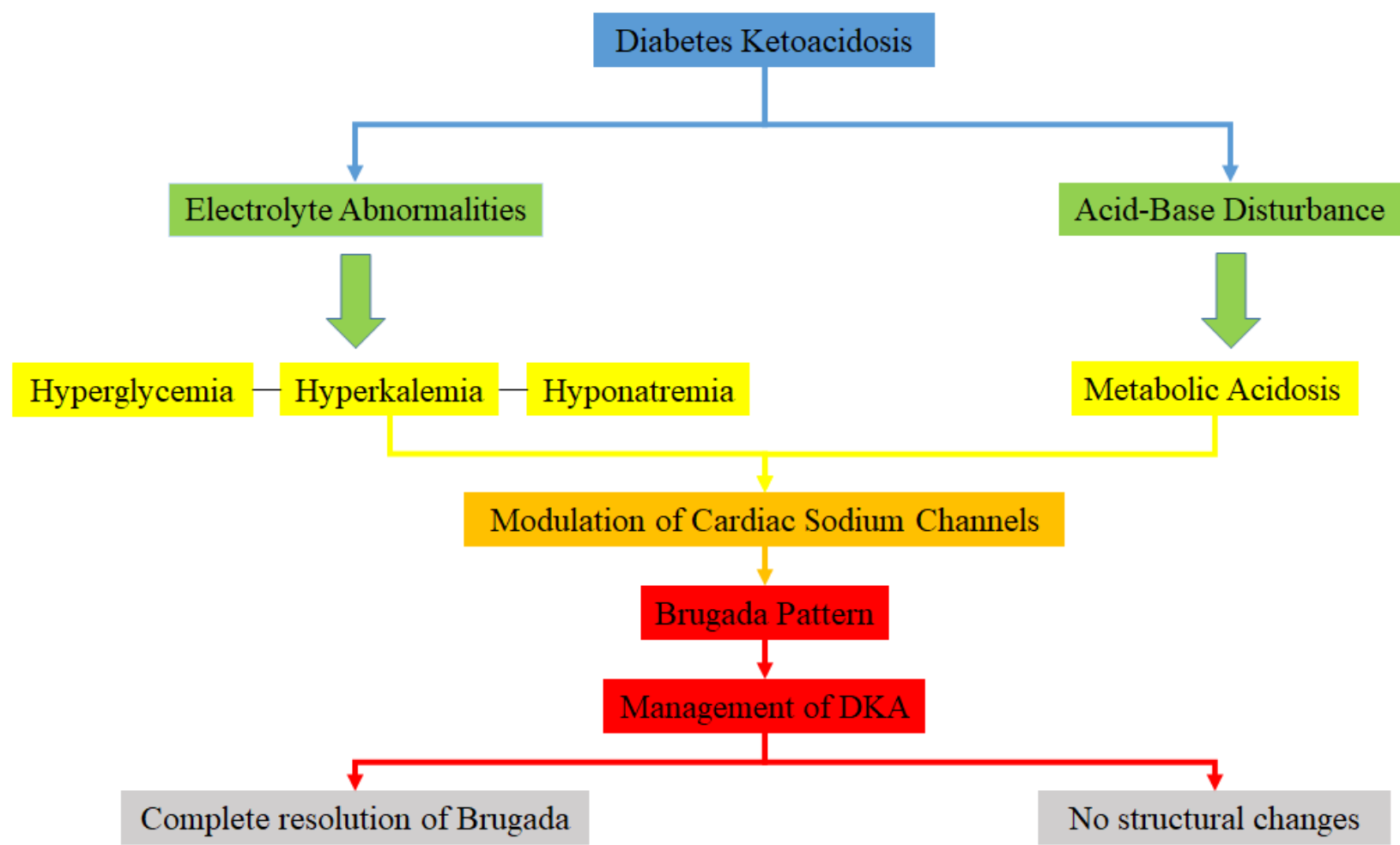

Figure 2. Etiopathogenesis of Brugada pattern in DKA

In our case, the Brugada pattern was elucidated in diabetic ketoacidosis with hyperkalemia and acidosis. In Table 3, we have reviewed 22 case reports that presented with a Brugada pattern in DKA initially concerning for a myocardial infarction. Similar to our case, the pattern resolved with the timely management of the underlying electrolyte disturbances. Furthermore, our review re-demonstrated a male predominance at a $\sim 7.33: 1$ male-female ratio with ages ranging from 7 to 72 . Mean and median values were calculated for age, $\mathrm{pH}$, glucose, sodium, potassium, and bicarbonate levels. The average age was found to be $\sim 45.9$ years, average $\mathrm{pH}$ on admission 
at 7.054 , average glucose $958.7 \mathrm{mg} / \mathrm{dl}$, average potassium for $7.424 \mathrm{mmol} / \mathrm{L}$, average sodium $123.6 \mathrm{mmol} / \mathrm{L}$, and average bicarbonate to be $7.7 \mathrm{mmol} / \mathrm{L}$. Our case showed that our patient was lower than average in age, $\mathrm{pH}$, and bicarbonate levels and greater than average in potassium and glucose levels. Some of the cases evaluated the cardiac function with transthoracic echocardiograms and they demonstrated no structural or valvular abnormalities which were consistent with our own echocardiogram findings. Others performed cardiac catheterization with normal coronaries. All cases had complete recovery once the DKA was treated and they bring to attention great importance in the close outpatient follow-up of diabetic management.

\section{Conclusion}

DKA may precipitate Brugada pattern in middle-aged men with no genetic predisposition. Brugada pattern will completely resolve on appropriate management of DKA. Acidosis and hyperkalemia in DKA promote electrophysiologic changes in the cardiac sodium channels producing a Brugada pattern/ coved ST-elevation mimicking acute myocardial infarction on an ECG. Brugada induction in electrophysiology laboratory often fails to induce Brugada pattern in such patients suggesting the Brugada pattern in these patients is due to DKA.

\section{Acknowledgements}

This work is sponsored in part by the Brooklyn Health Disparities Center NIH grant \#P20 MD006875.

\section{References}

[1] Wilde AA, Antzelevitch C, Borggrefe M, Brugada J, Brugada R, Brugada P, Corrado D, Hauer RN, Kass RS, Nademanee K, Priori SG. Proposed diagnostic criteria for the Brugada syndrome. European Heart Journal. 2002 Nov; 23(21): 1648.Patel SS, Anees SS, Ferrick KJ. Prevalence of a Brugada pattern electrocardiogram in an urban population in the United States. Pacing and Clinical Electrophysiology. 2009 Jun; 32(6): 704-8.

[2] Monroe MH, Littmann L. Two-year case collection of the Brugada syndrome electrocardiogram pattern at a large teaching hospital. Clinical cardiology. 2000 Nov; 23(11): 849-51.

[3] Bezzina CR, Rook MB, Wilde AA. Cardiac sodium channel and inherited arrhythmia syndromes. Cardiovascular research. 2001 Feb 1; 49(2): 257-71.

[4] Brugada R, Brugada J, Antzelevitch C, Kirsch GE, Potenza D, Towbin JA, Brugada P. Sodium channel blockers identify risk for sudden death in patients with ST-segment elevation and right bundle branch block but structurally normal hearts. Circulation. 2000 Feb 8; 101(5): 510-5.

[5] Brugada R, Campuzano O, Sarquella-Brugada G, Brugada J, Brugada P. Brugada syndrome. Methodist DeBakey cardiovascular journal. 2014 Jan; 10(1): 25.

[6] Matsuo K, Akahoshi M, Nakashima E, Suyama A, Seto S, Hayano $\mathrm{M}$, Yano K. The prevalence, incidence and prognostic value of the Brugada-type electrocardiogram: a population-based study of four decades. Journal of the American College of Cardiology. 2001 Sep 1; 38(3): 765-70.

[7] Anselm DD, Gottschalk BH, Baranchuk A. Brugada phenocopies: consideration of morphologic criteria and early findings from an international registry. Canadian Journal of Cardiology. 2014 Dec 1; 30(12): 1511-5.
[8] Kovacic JC, Kuchar DL. Brugada pattern electrocardiographic changes associated with profound electrolyte disturbance. Pacing and clinical electrophysiology. $2004 \mathrm{Jul} ; 2$ 27(7): 1020-3.

[9] Littmann L, Monroe MH, Taylor III L, Brearley Jr WD. The hyperkalemic Brugada sign. Journal of electrocardiology. 2007 Jan 1; 40(1): 53-9.

[10] Blom MT, Cohen D, Seldenrijk A, Penninx BW, Nijpels G, Stehouwer CD, Dekker JM, Tan HL. Brugada syndrome ECG is highly prevalent in schizophrenia. Circ Arrhythm Electrophysiol. 2014 Jun 1; 7(3): 384-91.

[11] Antzelevitch C, Brugada R. Fever and Brugada syndrome. Pacing and Clinical Electrophysiology. 2002 Nov; 25(11): 1537-9.

[12] González JR, Hernández AM, Garcia A, de Castro García A, Mejias A, Moro C. Recurrent ventricular fibrillation during a febrile illness in a patient with the Brugada syndrome. Revista espanola de cardiologia. 2000 May; 53(5): 755-7.

[13] Madle A, Kratochvil Z, Polivkova A. The Brugada syndrome. Vnitrni lekarstvi. 2002 Mar; 48(3): 255-8.

[14] Saura D, GARCÍA - ALBEROLA AR, Carrillo P, Pascual D, MARTÍNEZ - SÁNCHEZ JU, Valdes M. Brugada - like electrocardiographic pattern induced by fever. Pacing and Clinical Electrophysiology. 2002 May; 25(5): 856-9.

[15] PORRES JM, Brugada J, Urbistondo V, Garcia F, Reviejo K, Marco P. Fever unmasking the Brugada syndrome. Pacing and clinical electrophysiology. 2002 Nov; 25(11): 1646-8.

[16] Kum LC, Fung JW, Sanderson JE. Brugada syndrome unmasked by febrile illness. Pacing and clinical electrophysiology. $2002 \mathrm{Nov}$ 25(11): 1660-1.

[17] Ortega-carnicer J, Bertos-polo J, Gutiérrez-tirado C. Aborted sudden death, transient Brugada pattern, and wide Qrs dysrhythmias after massive Cocaine ingestion. Annals of Emergency Medicine. 2003 Mar 1; 41(3): 434-5.

[18] Littmann L, Monroe MH, Svenson RH. Brugada-type electrocardiographic pattern induced by cocaine. In Mayo Clinic Proceedings 2000 Aug 1 (Vol. 75, No. 8, pp. 845-849). Elsevier

[19] Doctorian T, Chou E. Cannabis-Induced Brugada Syndrome Presenting as Cardiac Arrest.

[20] Pratap B, Korniyenko A. Toxic effects of marijuana on the cardiovascular system. Cardiovascular toxicology. 2012 Jun 1; 12(2): 143-8.

[21] Alonso JV, Teo BH, del Pozo FJ, Aguayo MA, Sanchez A. Brugada electrocardiogram pattern induced by cannabis; is cannabis safe?. The American journal of emergency medicine. 2016 Aug 1; 34(8): 1738-e1.

[22] Kariyanna PT, Jayarangaiah A, Hegde S, Marmur JD, Wengrofsky P, Yacoub M, Post M, McFarlane SI. Marijuana Induced Type I Brugada Pattern: A Case Report. American Journal of Medical Case Reports. 2018; 6(7): 134-6.

[23] Darbar D, Yang T, Churchwell K, Wilde AA, Roden DM Unmasking of Brugada syndrome by lithium. Circulation. 2005 Sep 13; 112(11): 1527.

[24] Mitchell JE, Mackenzie TB. Cardiac effects of lithium therapy in man: a review. The Journal of clinical psychiatry. $1982 \mathrm{Feb}$.

[25] Mateer JR, Clark MR. Lithium toxicity with rarely reported ECG manifestations. Annals of emergency medicine. 1982 Apr 1; 11(4): 208-11.

[26] Rouleau F, Asfar P, Boulet S, Dube L, Dupuis JM, Alquier P, Victor J. Transient ST segment elevation in right precordial leads induced by psychotropic drugs: relationship to the Brugada syndrome. Journal of cardiovascular electrophysiology. 2001 Jan; 12(1): 61-5.

[27] Stirnimann G, Petitprez S, Abriel H, Schwick NG. Brugada syndrome ECG provoked by the selective serotonin reuptake inhibitor fluvoxamine. Europace. 2009 Oct 29; 12(2): 282-3.

[28] LÓPEZ-BARBEITO BE, Lluis $M$, Delgado V, Jimenez S, DÍAZ-INFANTE ER, NOGUÉ-XARAU SA, Brugada J. Diphenhydramine overdose and Brugada sign. Pacing and clinical electrophysiology. $2005 \mathrm{Jul} ; 28(7): 730-2$.

[29] Goldgran-Toledano D, Sideris G, Kevorkian JP. Overdose of cyclic antidepressants and the Brugada syndrome. New England Journal of Medicine. 2002 May 16; 346(20): 1591-2.

[30] Tomcsányi J, Simor T, Papp L. Haemopericardium and Brugada-like ECG pattern in rheumatoid arthritis. Heart. 2002 Mar 1; 87(3): 234.

[31] Khalil Y, Siddique SM, Hoang NT. A Brugada-pattern electrocardiogram and adrenal insufficiency. Annals of internal medicine. 2010 Dec 21; 153(12): 849. 
[32] Chawla KK, Cruz J, Kramer NE, Towne WD. Electrocardiographic changes simulating acute myocardial infarction caused by hyperkalemia: report of a patient with normal coronary arteriograms. American heart journal. 1978 May 1; 95(5): 637-40.

[33] Cohen A, Utarnachitt RV. Electrocardiographic changes in a patient with hyperkalemia and diabetic acidosis associated with acute anteroseptal pseudomyocardial infarction and bifascicular block. Angiology. 1981 May; 32(5): 361-4.

[34] Johnson CD. Electrocardiogram of the month. Pseudo-acute myocardial infarction. Boletin de la Asociacion Medica de Puerto Rico. 1983 Jun; 75(6): 288.

[35] Simon BC. Pseudomyocardial infarction and hyperkalemia: a case report and subject review. J Emerg Med 1988; 6: 511. 26.

[36] Kamimura M, Hancock EW. Acute MI pattern in diabetic ketoacidosis. Hospital practice (Office ed.). 1992 Dec 15; 27(12): 28.

[37] Sweterlitsch EM, Murphy GW. Acute electrocardiographic pseudoinfarction pattern in the setting of diabetic ketoacidosis and severe hyperkalemia. American heart journal. 1996 Nov 1; 132(5): 1086-9.

[38] Lim YH, Anantharaman V. Pseudo myocardial infarct-electrocardiographic pattern in a patient with diabetic ketoacidosis. Singapore medical journal. 1998 Nov; 39(11): 504-6.

[39] Milionis HJ, Dimos G, Elisaf MS. Severe hyperkalemia in association with diabetic ketoacidosis in a patient presenting with severe generalized muscle weakness. Nephrol Dial Transplant 2003; 18: 198

[40] Wang K. "Pseudoinfarction" pattern due to hyperkalemia. New England Journal of Medicine. 2004 Aug 5; 351(6): 593.

[41] Cook LK. An acute myocardial infarction? American Journal of Critical Care. 2005; 14: 313-315.
[42] Postema PG, Vlaar AP, DeVries JH, Tan HL. Familial Brugada syndrome uncovered by hyperkalaemic diabetic ketoacidosis. Europace. 2011 May 15; 13(10): 1509-10.

[43] Ersan T. Pseudo Brugada Pattern Due to Hyperkalemia. Journal of Clinical \& Experimental Cardiology. 2012; 01(s10).

[44] Franco E, Dias A, Teresa D, Hebert K. EKG pattern of Brugada syndrome and sudden infant death syndrome - is it time to review the diagnostic criteria? Case report and review of literature. Annals of Noninvasive Electrocardiology. 2014 Mar; 19(2): 198-202.

[45] Arunothayaraj S, Peters S, Kalman J. ST segment elevation due to Brugada pattern induced by hyperkalaemia during diabetic ketoacidosis. Heart, Lung and Circulation. 2015; 24.

[46] Maheshwari A, Von Wald L, Krishnan B, Benditt DG. Hyperkalemia-induced Brugada phenocopy. JACC: Clinical Electrophysiology. 2017 Mar 1: 330.

[47] Omar HR, El-Khabiry E, Dalvi P, Mangar D, Camporesi EM. Brugada ECG pattern during hyperkalemic diabetic ketoacidosis. Therapeutic advances in endocrinology and metabolism. 2017 Jan; 8(1-2): 20-1.

[48] Dendramis G, Petrina SM, Baranchuk A. Not all ST-segment elevations are myocardial infarction: Hyperkalemia and Brugada phenocopy. The American journal of emergency medicine. 2017 Apr 1; 35(4): 662-e1.

[49] Mehta N, Sharma P, Abdulsalam N, Schinlever M. TRANSIENT BRUGADA PATTERN IN DIABETIC KETOACIDOSIS. Journal of the American College of Cardiology. 2017; 11(69): 2319.

[50] Alanzalon RE, Burris JR, Vinocur JM. Brugada phenocopy associated with diabetic ketoacidosis in two pediatric patients. Journal of electrocardiology. 2018 Mar 1; 51(2): 323-6.

[51] Abrahim C, Maharaj S. DKA-induced Brugada phenocopy mimicking STEMI. Heart Asia. 2018 May 1; 10(2): e011027. 